\title{
AS REPRESENTAÇÕES SOCIAIS DA ASSISTÊNCIA ESTUDANTIL PARA ESTUDANTES BENEFICIADOS E NÃO BENEFICIADOS
}

\author{
Fernanda Maria de Oliveira ${ }^{1}$; http://orcid.org/0000-0001-9686-496X \\ Fauston Negreiros ${ }^{2}$; http://orcid.org/0000-0003-2046-8463 \\ Ludgleydson Fernandes de Araújo $^{3}$; http://orcid.org/0000-0003-4486-7565 \\ Raquel Pereira Belo ${ }^{4}$; http://orcid.org/0000-0003-2586-1563
}

\begin{abstract}
Resumo
A Política Nacional de Assistência Estudantil- PNAES constitui-se em uma das políticas educacionais que têm contribuído para o desenvolvimento de diversas ações no cenário educacional brasileiro, visando à ampliação da permanência do aluno na Educação Superior. Nesta perspectiva, o presente estudo objetivou compreender as representações sociais da Assistência Estudantil para estudantes beneficiados e não beneficiados, em uma Instituição de Ensino Superior (IES) pública. A coleta de dados foi feita com 100 participantes, utilizando-se a Técnica de Associação Livre de Palavras - TALP, com a apresentação de uma palavra-estímulo, no caso, Assistência Estudantil, e em seguida o questionário sociodemográfico. A análise dos dados obtidos pela TALP foi feita a partir da rede semântica e as informações contidas nos questionários foram analisadas por meio do software SPSSWIN, versão 21, obtendo-se a caracterização do perfil sociodemográfico da amostra. Os resultados apontaram que os estudantes beneficiados e não beneficiados têm a representação social da Assistência Estudantil como uma ajuda e estando associada à renda, respectivamente. Essas compreensões apontam para o desconhecimento por parte de alguns alunos sobre um conjunto de ações que devem ser desenvolvidas por esta política pública para viabilizar a igualdade de oportunidades, de forma a contribuir para melhorar o desempenho acadêmico, atuando de maneira preventiva sobre as situações de retenção e evasão escolar pelos estudantes que apresentam vulnerabilidade socioeconômica. Portanto, deve-se pensar como as políticas educacionais estão afetando o ambiente universitário e qual o entendimento que se tem sobre estas, para que haja, de fato, sua efetivação, neste contexto.

Palavras-chave: Assistência Estudantil; Ensino Superior; Políticas Educacionais.
\end{abstract}

\section{The social representations of student assistance for benefited and not benefited students}

\begin{abstract}

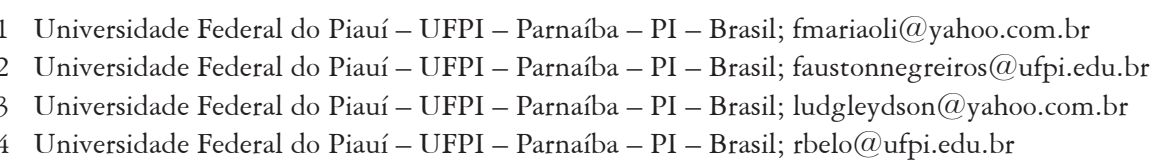

The National Student Assistance Policy - PNAES is one of the educational policies that have been contributing to the development of several actions in the Brazilian educational scenario, aiming at expanding the student's permanence in Higher Education. In this perspective, the present study aimed to understand the social representations of Student Assistance for benefited and not benefited students, in a Public Higher Education Institution (IES). Data collection wascarried out with 100 participants, using the Free Word Assiciation Technique- TALP, with the presentation of a stimulus word, in this case, Student Assistance, and then the sociodemographic questionnaire. The data analysis obtained by the TALP was made from the semantic chain and the information contained in the questionnaires was analyzed using the SPSSWIN software, version 21, obtaining the characterization of the sample's sociodemographic profile. The results showed that the benefited and not benefited students have the social representation of Student Assistance as a support and associated with income, respectively. These understandings point to the lack of knowledge of some students about a set of actions that must be developed by this public policy to enable equal opportunities, in order to contribute to improve academic performance, acting in a preventive manner on retention situations and evasion school by students 
with socioeconomic vulnerability. Therefore, it is necessary to think about how educational policies are affecting the university environment, and what is the understanding about them, so that, in fact, its effectuation in this context. keywords: Student Assistance; Higher education; Educational Policies.

\section{Las representaciones sociales de la asistencia estudiantil para estudiantes beneficiados y no beneficiados}

\section{Resumen}

La Política Nacional de Asistencia Estudiantil-PNAES constituyese en una de las políticas educativas que han contribuido en el desarrollo de diversas acciones en el escenario educativo brasileño, visando la ampliación de la permanencia del alumno en la Educación Superior. En esta perspectiva, el presente estudio objetivó comprender representaciones sociales de la Asistencia Estudiantil para estudiantes beneficiados y no beneficiados, en una Institución de Enseñanza Superior (IES) pública. La recolección de datos ocurrió con 100 participantes, utilizando la Técnica de Asociación Libre de Palabras - TALP, con presentación de una palabra-estímulo, en este caso, Asistencia Estudiantil, y luego el cuestionario sociodemográfico. El análisis de datos obtenidos por la TALP se realizó a partir de la red semántica y la información contenida en los cuestionarios fue analizada por el software SPSSWIN, versión 21, obteniéndose la caracterización del perfil sociodemográfico de la amuestra. Resultados apuntaron que estudiantes beneficiados y no beneficiados tienen la representación social de la Asistencia Estudiantil como un apoyo y está asociado a la renta, respectivamente. Esas comprensiones apuntan para el desconocimiento de algunos alumnos sobre un conjunto de acciones que deben ser desarrolladas por esta política pública para viabilizar la igualdad de oportunidades, para contribuir para mejoramiento del desempeño académico, actuando de manera preventiva sobre situaciones de retención y evasión escolar por los estudiantes que presentan vulnerabilidad socioeconómica. Así, se debe pensar cómo las políticas educativas están afectando el ambiente universitario, y cuál es el entendimiento que se tiene, para que haya, de hecho, su efectividad, en este contexto. Palabras clave: Asistencia estudiantil; Enseñanza superior; Políticas Educativas.

\section{Introdução}

As ideias elaboradas como representações sociais apresentam-se como uma noção, que antes era interpretada como algo reservado às sociedades tradicionais e atualmente passam a fazer parte também da sociedade moderna, porém sob um novo olhar, sendo reconhecidas como conviç̧ões que são construídas e adquiridas, ao contrário de um lado preestabelecido e estático que se adotava sobre estas, próprio de uma visão clássica. O fenômeno da representação social, representando uma coisa ou uma noção, não se refere à produção única de nossas ideias próprias e imagens, mas sim, a uma criação e transmissão de um produto que se elabora de diversos lugares, a partir de várias regras (Moscovici, 2001).

Sendo assim, mesmo que seja unânime a discussão sobre a educação como um direito para todos e reconhecendo-se que a humanização dos indivíduos dá-se a partir de uma educação escolar com qualidade, também é fato que, historicamente, tem ocorrido o enfrentamento a muitos elementos, que se apresentam como obstáculos à construção de processos educacionais importantes para que se possa garantir a todos os estudantes o acesso ao conhecimento. Nesta perspectiva, destacam-se alguns estudos sobre o processo de escolarização que apontam para a importância de investigarem-se as políticas públicas educacionais, compreendendo suas concepções, como se materializam no cotidiano escolar e, com isso, influenciam também a construção destes espaços (Zibetti, Pacífico \& Tamboril, 2016).

Em seu estudo, Gebrim (2014) destaca que na Declaração Mundial da Educação Superior para o Século XXI, estão prescritas a necessidade de expansão, melhoramento e contextualização da educação, considerando-se demandas contemporâneas e devendo ser feitas a partir disso, para então, fomentar as transformações sociais que se fizerem necessárias nesse ambiente, enfocando-se também sua sustentabilidade. Apesar disso, enfatiza que os avanços foram parciais na democratização do acesso ao contexto acadêmico, por isso, surgiu a necessidade de criação de políticas públicas direcionadas para a minimização das diferenças socioeconômicas que dificultavam o acesso ao 
ensino superior, marcando um processo de expansão e democratização na oferta de vagas nos cursos superiores no Brasil.

A implementação de políticas educacionais no Ensino Superior favoreceu um importante crescimento desse cenário, caracterizado, nas últimas décadas, por um processo intenso de ampliação e democratização do acesso e permanência nesse contexto. No entanto, Neves (2012) aponta um paradoxo em relação a um crescimento óbvio e perceptível desse nível de ensino no Brasil, que pode ser absoluto em alguns aspectos, porém mostra-se insuficiente quando comparado ao que a população almeja em relação ao seu alcance e expansão, necessários para atender suas expectativas.

Diéguez (2015) destaca o Programa Universidade para Todos-Prouni e o Financiamento Estudantil-FIES e a Reestruturação e Ampliação das Instituições Federais de Ensino-REUNI, onde foi possível, a partir de então, promover a interiorização das universidades e o aumento do número de cursos e vagas, sendo assim, os mais jovens puderam ingressar na graduação. No entanto, esta expansão que ocorreu nesse cenário, nas últimas décadas, foi fortemente marcada pelo crescente número de instituições, cursos, vagas, ingressantes, matrículas e concluintes. Sendo esse crescimento constante e muito significativo, porém acelerado no período de 1999 a 2003, com altas taxas de crescimento na Educação Superior, principalmente em virtude do surgimento de instituições privadas nessa modalidade de ensino. Entretanto, nos anos seguintes, ocorreu uma manutenção do crescimento, porém mais voltado para atender às políticas globais de inclusão social, ou seja, a expansão dar-se-á mais direcionada à democratização, orientada por um conjunto de políticas estruturantes vigentes nos últimos anos (Ristoff, 2014).

Bisinoto e Marinho-Araújo (2014) apontam que a maneira como a instituição está organizada, sua gestão, infraestrutura, serviços de apoio disponibilizados aos discentes, as atividades pedagógicas e extracurriculares, as políticas educativas, bem como as ideologias inerentes ao contexto educacional, atravessam todo o processo de formação e as trajetórias dos estudantes e constituem-se como fatores envolvidos no sucesso acadêmico. Ressaltam também a importância de fatores considerados individuais, trazidos pelos discentes para dentro da instituição, referentes às variáveis cognitivas, de funcionamento psicológico e as relações interpessoais. Deve-se considerar fatores institucionais de flexibilização curricular, buscando a adequação às necessidades dos alunos, diversificando estratégias didáticas e os modelos avaliativos, buscando a qualificação docente, aumentando a oferta de serviços de apoio e orientação acadêmica, além de disponibilizar espaços e materiais necessários para desenvolverem-se atividades acadêmicas.

O primeiro ano de universidade apresenta-se como desafiador para o estudante de qualquer origem social podendo resultar em fracasso ou abandono, com isso, um estudo na Universidade Federal da Bahia, tentou compreender o universo relacional, subjetivo e interacional dos estudantes ingresso a partir de suas narrativas recolhidas, dessa forma conseguiu-se pistas importantes sobre o desenho de políticas voltadas não apenas para a entrada do aluno na universidade, mas também para sua permanência e convivência com sucesso nesse espaço educativo (Sampaio, 2009).

O Decreto $\mathrm{n}^{\circ} 7.234 / 2010$ dispóe sobre o Programa Nacional de Assistência Estudantil-PNAES que tem como finalidade a ampliação das condições de permanência dos estudantes na educação superior pública federal. Por meio do PNAES, as Instituições Federais de Ensino-IFES buscam desenvolver ações para atenderem às necessidades dos discentes por meio de 10 áreas estratégicas: moradia estudantil; alimentação; transporte; atenção à saúde; inclusão digital; cultura; esporte; creche; apoio pedagógico; acesso, participação e aprendizagem de estudantes com deficiência, transtornos globais do desenvolvimento e altas habilidades e superdotação. A Assistência Estudantil tem contribuído para a permanência do estudante na graduação oferecendo-lhes apoio financeiro, educacional, psicológico e de saúde, para alunos advindos de classes sociais que historicamente foram excluídas da Educação Superior e que sem esse apoio não teriam condições de concluir seus estudos, nesse nível de ensino (Oliveira, 2016).

Em relação a isso, Lima (2013) aponta discussões sobre a necessidade de se pensar a melhoria da qualidade das universidades afirmando que isso não pode ser feito apenas, a partir de sistemas e programas destinados a apresentar resultados, muito menos com políticas focais que visam à resolutividade dos problemas da educação superior brasileira. Com isso, defende que o acesso ao Ensino Superior, principalmente nas instituições públicas, ainda é uma realidade, por ser um processo que antecede à entrada do aluno neste contexto. Pensar a democratização do acesso, permanência e conclusão de cursos superiores, principalmente 
para a maior parte da população, é desenvolver um trabalho de base, que possa incluir também aspectos relacionados à organização, estrutura e funcionamento da oferta.

Diante dessa realidade que envolve os desafios da democratização do acesso e da permanência dos estudantes no Ensino Superior, objetivou-se neste estudo, compreender as representações sociais da Assistência Estudantil por estudantes beneficiados e não beneficiados, uma vez que o PNAES tem se constituído como uma importante política de enfrentamento às situações de evasão escolar.

\section{Método}

\section{Participantes}

Esta pesquisa contou com 100 participantes oriundos de uma Instituição de Ensino Superior (IES) pública, sendo 50 estudantes beneficiados pela Assistência Estudantil e 50 estudantes não beneficiados pela Assistência Estudantil. Estes foram selecionados de forma aleatória e não probabilística. Os critérios de inclusão para participar desta pesquisa foram: 1) receber benefícios remunerados da Assistência Estudantil ou ser contemplado com a Residência Estudantil Universitária - REU; 2) não ter solicitado nenhum benefício da Assistência Estudantil. Consideraram-se como critérios de exclusão: ter solicitado qualquer um dos benefícios da Assistência Estudantil e não ter sido selecionado.

\section{Instrumentos}

Neste estudo, foi utilizada a Técnica de Associação Livre de Palavras-TALP com a apresentação de uma palavra-estímulo Assistência Estudantil. Realizaram-se também questionários compostos por orientação ao participante em relação ao objetivo da pesquisa e questões necessárias para a elaboração do perfil sociodemográfico.

\section{Procedimentos de coleta}

Os participantes foram esclarecidos sobre os objetivos da pesquisa, destacando-se o caráter voluntário da participação e o sigilo das informações. Estes foram orientados sobre a utilização da Técnica de Associação Livre de Palavras - TALP para que pudessem responder a uma palavra-estímulo apresentada, no caso, Assistência Estudantil, no qual deveriam escrever as cinco primeiras palavras que lhe viessem à mente, relacionadas à palavra mencionada como estímulo, devendo enumerá-las de 1 a 5 , conforme a ordem de importância. A TALP é uma técnica projetiva, proveniente da psicanálise, empregada com o intuito de fazer emergir de forma espontânea o pensamento, livre das racionalizações ou dos bloqueios da censura. Como uma técnica característica da pesquisa qualitativa a TALP é comumente utilizada em investigações científicas como, por exemplo, no estudo das representações sociais de determinados fenômenos (Bardin, 2011). A aplicação da técnica é relativamente simples: como instrução ao participante da pesquisa solicita-se que ele escreva as primeiras cinco palavras que lhe vier à mente quando o pesquisador pronuncia a palavra-estímulo e, em seguida, pede-se para hierarquizar as palavras por ordem de importância, sendo número 1 a palavra mais importante e 5 a menos importante. A TALP tem como vantagem o fato de permitir acessar conteúdos a nível inconsciente, obtidos por meio das respostas que o sujeito não daria caso tivesse conhecimento prévio da palavra-estímulo. Desse modo, com a TALP as respostas são apresentadas de forma mais autentica (Bardin, 2011).

Em seguida os participantes responderam às perguntas referentes aos dados sociodemográficos, necessários para caracterizar a amostra, a fim de obterem-se informações sobre idade, sexo, estado civil, filhos, curso e período, com quem reside, em que tipo de escola cursou o Ensino Médio e sua forma de acesso à Instituição.

\section{Análise dos Dados}

A caracterização da amostra foi feita por meio do pacote estatístico SPSSWIN, versão 21, através das análises de estatísticas descritivas, com isso, obteve-se o perfil sociodemográfico dos participantes, conforme apresentado na Tabela 1.

Para analisar os dados obtidos utilizando-se a TALP, organizou-se, primeiramente, um conjunto de palavras relacionadas à palavra-estímulo Assistência Estudantil, formando-se uma rede semântica. Para Vera-Noriega, Pimentel e Batista de Albuquerque (2005), as redes de significados ou redes semânticas referem-se às concepções que as pessoas têm sobre algum objeto em seu entorno, possibilitando uma leitura cuidadosa do pensamento coletivo sobre 
determinado construto. Isso se dá supondo-se que as pessoas desenvolvem estruturas cognitivas, que são estruturas psicológicas de conhecimento relacionadas às crenças, opiniões, expectativas, hipóteses, teorias, esquemas, que as pessoas usam para interpretar estímulos, ao mesmo tempo em que suas reações são mediadas por essas interpretações. Segundo os autores, a investigação por redes semânticas, que se dá atualmente na psicologia, enfatiza de forma preponderante, os processos cognitivos e a maneira como se apreende a estrutura dessa informação. Assim, essa técnica possibilita o acesso à organização cognitiva do conhecimento, de forma empírica.

A partir desse entendimento sobre rede semântica, foram criadas duas tabelas, correspondendo aos dados de cada grupo, com as cinco palavras mais representativas apontadas pelos participantes. Em seguida os dados foram organizados no Núcleo da Rede (NR) e depois atribuídos o Peso Semântico (PS) e a Distância Semântica Quantitativa (DSQ). Os resultados obtidos em relação aos alunos beneficiados e os alunos não beneficiados estão apresentados nas Tabelas 2 e 3, respectivamente.

\section{Resultados}

Os participantes desta pesquisa constituíram dois grupos. No Grupo composto por 50 alunos beneficiados, a maioria dos participantes é do sexo feminino (60\%), com idade variando de 18 a 36 anos $(M=21,22 ; D P=3,43)$, sendo solteiros (90\%) e sem nenhum filho (96\%). Em relação ao grupo composto por alunos não beneficiados, também com 50 participantes, observou-se que a maioria foi do sexo feminino (54\%), com idade variando entre 18 e 36 anos $(M=21,04 ; D P=4,21)$, solteiros $(86 \%)$ e não possuem filhos (92\%). Os demais dados sociodemográficos correspondentes aos dois grupos podem ser observados na Tabela 1.

Tabela 1

Dados sociodemográficos dos estudantes beneficiados e não beneficiados pela Assistência Estudantil

\begin{tabular}{|c|c|c|c|c|}
\hline \multirow{2}{*}{ Variável } & \multicolumn{2}{|c|}{ Alunos beneficiados } & \multicolumn{2}{|c|}{ Alunos não beneficiados } \\
\hline & Frequência & $\%$ & Frequência & $\%$ \\
\hline \multicolumn{5}{|l|}{ Sexo } \\
\hline Feminino & 30 & 60,0 & 27 & 54,0 \\
\hline Masculino & 20 & 40,0 & 23 & 46,0 \\
\hline \multicolumn{5}{|l|}{ Estado civil } \\
\hline Solteiro (a) & 45 & 90,0 & 43 & 86,0 \\
\hline Casado (a) & 3 & 6,0 & 2 & 4,0 \\
\hline Outro & 2 & 4,0 & 5 & 10,0 \\
\hline \multicolumn{5}{|l|}{ Filhos } \\
\hline Nenhum & 46 & 96,0 & 46 & 92,0 \\
\hline 1 filho & 3 & 6,0 & 3 & 6,0 \\
\hline Mais de 2 filhos & 1 & 2,0 & 1 & 2,0 \\
\hline \multicolumn{5}{|l|}{ Curso } \\
\hline Psicologia & 12 & 24,0 & 13 & 26,5 \\
\hline Ciências econômicas & 10 & 20,0 & 14 & 28,6 \\
\hline Ciências biológicas & 8 & 16,0 & - & - \\
\hline Pedagogia & 8 & 16,0 & 9 & 18,4 \\
\hline Engenharia de Pesca & 5 & 10,0 & - & - \\
\hline Ciências Contábeis & 3 & 6,0 & 13 & 26,5 \\
\hline Biomedicina & 2 & 4,0 & - & - \\
\hline Turismo & 1 & 2,0 & - & - \\
\hline Fisioterapia & 1 & 2,0 & - & - \\
\hline
\end{tabular}




\begin{tabular}{|c|c|c|c|c|}
\hline \multirow{2}{*}{ Variável } & \multicolumn{2}{|c|}{ Alunos beneficiados } & \multicolumn{2}{|c|}{ Alunos não beneficiados } \\
\hline & Frequência & $\%$ & Frequência & $\%$ \\
\hline \multicolumn{5}{|l|}{ Período } \\
\hline $1^{\circ}$ & 2 & 4,4 & - & - \\
\hline $2^{\circ}$ & 13 & 28,9 & 34 & 70,8 \\
\hline $3^{\circ}$ & - & - & 1 & 2,1 \\
\hline $4^{\circ}$ & 16 & 35,6 & 11 & 22,9 \\
\hline $5^{\circ}$ & 3 & 6,7 & 1 & 2,1 \\
\hline $6^{\circ}$ & 1 & 2,2 & - & - \\
\hline $7^{\circ}$ & 3 & 6,7 & - & - \\
\hline $8^{\circ}$ & 5 & 11,1 & - & - \\
\hline $9^{\circ}$ & 1 & 2,2 & 1 & 2,1 \\
\hline $10^{\circ}$ & 1 & 2,2 & - & - \\
\hline \multicolumn{5}{|l|}{ Reside } \\
\hline Família/Companheiro & 20 & 40,0 & 32 & 64,0 \\
\hline Amigo & 18 & 36,0 & 13 & 26,0 \\
\hline Outro & 12 & 24,0 & 5 & 10,0 \\
\hline \multicolumn{5}{|c|}{ Onde estudou no Ensino Médio } \\
\hline Escola pública & 42 & 84,0 & 20 & 40,0 \\
\hline Escola privada & 5 & 10,0 & 23 & 46,0 \\
\hline Escola privada com bolsa & 1 & 2,0 & 7 & 14,0 \\
\hline Outro & 2 & 4,0 & - & - \\
\hline \multicolumn{5}{|c|}{ Forma de acesso à Instituição } \\
\hline SISU (Cota social) & 30 & 60,0 & 11 & 22,0 \\
\hline SISU & 20 & 40,0 & 36 & 72,0 \\
\hline Outro & - & - & 3 & 6,0 \\
\hline
\end{tabular}

Fonte: dados da pesquisa

\section{Alunos beneficiados pela assistência estudantil}

De acordo com os resultados obtidos neste grupo, por meio da análise utilizando-se o recurso da rede semântica, em relação à representação da Assistência Estudantil para os estudantes beneficiados, pode-se observar que com o maior peso semântico, a palavra ajuda foi a que mais teve representatividade, com distância semântica de $100 \%$. Seguida pela palavra colaboração (68\%), apoio (51\%), assistência (23\%), e associado à renda (10\%).

A literatura aponta que o empreendimento de políticas nos últimos 20 anos contribuiu para modificar o acesso ao Ensino Superior no Brasil, abrindo oportunidades para os jovens, principalmente aqueles de baixa renda buscarem melhor qualificação para o mercado de trabalho, melhorando seu processo de escolarização (Diéguez, 2015).

A Assistência Estudantil percebida pela maioria dos participantes desta pesquisa como uma ajuda precisa ser repensada, pois reflete um possível desconhecimento por parte de alguns alunos sobre o conjunto de ações que devem ser desenvolvidas por esta política, visando à ampliação das condições de permanência dos estudantes no Ensino Superior (PNAES, 2010).

O reconhecimento da Assistência Estudantil como uma política para garantir direitos faz-se necessário e já contribuiu bastante para a efetivação do processo de reestruturação e expansão das universidades, uma vez que sua implementação propiciou pensar estratégias por gestores e equipes multiprofissionais das IES públicas, havendo maior preocupação com o estudante universitário, tornando mais relevante ainda a existência dessas políticas educacionais nesse contexto (Oliveira, 2016).

A Assistência Estudantil é uma política que zela pela permanência do estudante na educação superior das Instituições Federais de Ensino Superior -IFES (PNAES, 2010), segundo Zibetti et al (2016), as políticas públicas educacionais produzidas a partir de 1988, voltadas para o enfrentamento de dificuldades 
no âmbito escolar são orientadas pelo princípio da educação como direito universal, com isso, cabe ao Estado criá-las e implementá-las para que esse direito possa ser garantido, com destaque para um dos princípios fundamentais declarados na Constituição, no inciso I, que trata da igualdade de direitos para a acesso e permanência na escola.

Diéguez (2015) assinala que até os anos 2000 pôde-se observar um processo de expansão mas, que não foi suficiente para os jovens buscarem seu ingresso na universidade de forma efetiva, principalmente aqueles considerados de baixa renda. Entretanto, pode-se perceber, que nos anos posteriores a 2003, a implantação de políticas públicas referentes ao Ensino Superior que contribuíram para efetivar e ampliar o acesso a este espaço. Segundo Neves (2012) a partir de 2005 torna-se mais evidente, embora com pequena visibilidade ainda, que houve um crescimento da presença de alunos considerados de baixa renda, tanto nos setores públicos de ensino quanto nos privados, e esse fenômeno foi observado como um processo resultante da implantação de programas de inclusão social nas IES.

Dentre as diversas políticas educacionais que contribuíram para formar o novo cenário na Educação Superior diferente do que se costumava ver em relação ao corpo discente que compunha e ocupava os cursos de graduação e licenciatura, Sampaio (2009) aponta para um novo grupo advindo do sistema de cotas, porém ressalta algumas preocupações em relação ao ingresso desses estudantes na universidade, devendo-se atentar, pois geralmente carregam uma insegurança a respeito de sua competência provocando muitos questionamentos se essa seria a melhor maneira de acessar a Educação Superior, pois para alguns seria difícil assumir que seu ingresso na universidade deu-se através desse regime de cotas, em virtude de forte relação que ainda existe entre cotas-incompetência, até mesmo por aqueles que usufruíram desse direito.

Bisinoto e Marinho-Araújo (2014) evidenciam os fatores inerentes ao sucesso acadêmico devem ser vistos para além do desempenho dos alunos, por ser um processo mais complexo e multideterminado, constituído pela comunidade acadêmica, sociedade e governo, não devendo ser tratado por uma perspectiva individualizada no qual o estudante é visto apenas por obter êxito ou fracasso.

Os resultados indicaram que a maioria dos estudantes beneficiados pela Assistência Estudantil ingressou na universidade pela política de cotas, isso pode apontar para um público que atende às exigências da Política Nacional de Assistência Estudantil, talvez isso implique no número de pessoas beneficiadas presente na amostra do presente estudo. Sobre esse ponto, Lima (2013) enfatiza não haver dúvidas sobre a urgência no estabelecimento de políticas de democratização no Ensino Superior, sendo esse processo também decisivo para ajudar a romper com a educação historicamente elitizada e enraizada.

Continuando com essa discussão, porém a partir de outro grupo participante nesta pesquisa, será apresentado a seguir, como a literatura aborda as questões que emergiram dos resultados apresentados e que também contribuíram para o alcance do objetivo proposto neste estudo.

Tabela 2

Rede semântica Alunos Beneficiados pela Assistência Estudantil

\begin{tabular}{ccc}
\hline $\begin{array}{c}\text { Núcleo da Rede } \\
\text { (NR) }\end{array}$ & $\begin{array}{c}\text { Peso Semântico } \\
\text { (PS) }\end{array}$ & $\begin{array}{c}\text { Distancia Semântica Quantitativa } \\
\text { (DSQ) }\end{array}$ \\
\hline Ajuda & 70 & $100 \%$ \\
Colaboração & 48 & $68 \%$ \\
Apoio & 36 & $51 \%$ \\
Assistência & 16 & $23 \%$ \\
Renda & 07 & $10 \%$ \\
\hline
\end{tabular}

Fonte: dados da pesquisa 


\section{Alunos não beneficiados pela assistência estudantil}

A Assistência Estudantil foi representada pelo grupo de estudantes não beneficiados, por sua maioria, como uma renda, palavra mencionada com maior peso semântico e distância semântica de 100\%. Assim, observou-se que para estes participantes a política de Assistência Estudantil estaria voltada para atender às necessidades dos alunos de baixa renda ou, mais especificamente, teria a finalidade de contribuir financeiramente com o aluno por meio de benefícios remunerados.

No entanto, Gebrim (2014) enfatiza a necessidade de ser pensando para além do auxílio financeiro que alguns alunos recebem para estudar, para garantir o sucesso discente são necessários investimentos no desenvolvimento de técnicas, didáticas e outras abordagens pedagógicas que possam promover a capacitação dos professores e técnicos para desta forma possam atuar na perspectiva da diversidade.

Ristoff (2014) afirma que a implementação de políticas educacionais que promoveram o processo de criação de novas universidades e a intensa interiorização, tem contribuído para o início de uma mudança no perfil socioeconômico dos estudantes universitários. O autor ressalta que há uma diminuição cada vez maior no número de estudantes ricos que ingressam no ensino superior público, que pode ser observado como um resultado dos efeitos das políticas de inclusão vigentes. Diéguez (2015) destaca as ações do Governo Federal para melhorar a educação superior nos últimos 20 anos por meio de políticas que melhorassem o acesso à esse nível educacional, com destaque para o Exame Nacional do Ensino Médio-ENEM, o Sistema de Seleção Unificada-SISU, o FIES e o Prouni e que além do ingresso, tem beneficiado também a permanência de jovens, mais precisamente de 18 a 24 anos, considerada a faixa etária padrão.

As ações desenvolvidas pelo PNAES (2010) consideram a igualdade de oportunidades devendo atuar tanto para melhorar o desempenho acadêmico, como também precisa agir de forma preventiva sobre as situações de retenção e evasão que sejam decorrentes da insuficiência de condições financeiras dos estudantes. Nesta perspectiva, Ristoff (2014) enfatiza que se deve considerar como um fator determinante para a trajetória de jovens na Educação Superior brasileira, sua origem social e a situação socioeconômica familiar, em virtude do processo histórico de exclusão sofrido por alguns grupos, e que por este motivo devem constituir a base das políticas públicas de inclusão.

Neves (2012) aponta uma relação inversamente proporcional caracterizado por um grande aumento do investimento público e privado, para esse nível educacional e uma diminuição do ritmo de crescimento de matrículas, enfatizando-se aqui os desafios e os problemas da permanência do estudante para a conclusão do seu curso, como pontos que ainda não foram superados. Entretanto, Ristoff (2014) ressalta que uma mudança do perfil socioeconômico da graduação já foi observada a partir do terceiro ciclo do Exame Nacional de Desempenho dos Estudantes-ENADE, mantendo-se nos últimos anos de forma acelerada. Essa realidade evidencia que os grupos excluídos historicamente têm se beneficiado das políticas públicas, embora tenham disso lentas em sua execução. Isso tem proporcionado uma mobilidade social advinda de oportunidades para alunos trabalhadores, de baixa renda, pretos pardos, indígenas, e filhos de pais sem escolaridade.

Vários estudos têm sido realizados nas últimas décadas interessados nos fatores que possivelmente estejam afetando o (in)sucesso dos discentes na Educação Superior, e que esse interesse é explicado em virtude do amplo e intenso processo de democratização do acesso a esse contexto educacional (Bisinoto \& Marinho-Araújo, 2014). Sampaio (2009) destaca que não se devem restringir as ações voltadas para a permanência de estudantes apenas ao âmbito socioeconômico, também devem ser desenvolvidas ações para atender às necessidades pedagógicas e acadêmicas a partir do reconhecimento e valorização dos percursos acadêmicos desse público considerando-se suas experiências escolares e existenciais.

O PNAES (2010) prevê ações visando à viabilização da igualdade de oportunidades, dentre outras questões inerentes à permanência do aluno em seu curso superior, como por exemplo, busca contribuir com a melhoria do desempenho acadêmico, e precisa agir de forma preventiva nas situações de retenção e evasão escolar, que possam surgir em virtude de condições financeiras precárias.

Dessa forma, esse estudo buscou compreender as representações sociais de estudantes em relação à Assistência Estudantil apresentado resultados importantes sobre o entendimento dessa política educacional no contexto universitário. 
Tabela 3

Rede semântica acerca Alunos não Beneficiados pela Assistência Estudantil

\begin{tabular}{ccc}
\hline $\begin{array}{c}\text { Núcleo da Rede } \\
\text { (NR) }\end{array}$ & $\begin{array}{c}\text { Peso Semântico } \\
\text { (PS) }\end{array}$ & $\begin{array}{c}\text { Distância Semântica Quantitativa } \\
(\text { DSQ) }\end{array}$ \\
\hline Renda & 55 & $100 \%$ \\
Auxilio & 28 & $50 \%$ \\
Cooperação & 21 & $38 \%$ \\
Dinheiro & 14 & $25 \%$ \\
Ajuda & 05 & $09 \%$ \\
\hline
\end{tabular}

Fonte: dados da pesquisa

\section{Discussão}

O presente estudo indicou a representação social que os estudantes beneficiados e não beneficiados têm sobre a Assistência Estudantil. Pode-se observar que esta não foi apontada pelos participantes como um direito, sendo mais associada à ajuda e a renda. No entanto, estudos apresentados nesta pesquisa possibilitaram compreender a Assistência Estudantil como umas das políticas educacionais que contribuíram para o processo de expansão e interiorização da educação superior no país, sendo responsável por desenvolver estratégias de permanência de estudantes em vulnerabilidade socioeconômica.

Algumas limitações foram observadas nesta pesquisa, dentre elas, destacam-se o número de participantes e de cursos que representaram um público ainda pouco expressivo para o que se pretendia estudar. Com isso, orienta-se a aplicabilidade desta pesquisa para uma quantidade maior de representantes discentes.

Ressalta-se a necessidade de discutirem-se as políticas educacionais como uma questão de direitos, bem como conhecer os contextos históricos em que elas emergiram e os atuais que as mantém ou as ameaçam. Sendo o Ensino Superior um espaço favorável para se pensar e refletir sobre essas questões e o quanto elas têm contribuído para modificar o cenário educacional, antes elitizado, porém ainda excludente, mesmo com o discurso de democratização do acesso e da permanência, que tem sido garantido em alguns aspectos, mas que ainda se apresenta fragilizado diante de fatores políticos, econômicos, culturais, históricos e sociais.

Os resultados apontaram que os estudantes beneficiados e não beneficiados têm a representação social da Assistência Estudantil como uma ajuda e estando associada à renda, respectivamente. Essas compreensões apontam para o desconhecimento por parte de alguns alunos sobre um conjunto de ações que devem ser desenvolvidas por esta política pública para viabilizar a igualdade de oportunidades, de forma a contribuir para melhorar o desempenho acadêmico, atuando de maneira preventiva sobre as situações de retenção e evasão escolar pelos estudantes que apresentam vulnerabilidade socioeconômica.

Portanto, deve-se pensar como as políticas educacionais estão afetando o ambiente universitário, e qual o entendimento que se tem sobre estas, para que haja, de fato, sua efetivação, neste contexto.

\section{Referências}

Bardin, L. (2011). Análise de conteúdo. São Paulo, SP: Edições 70.

Bisinoto, C., Marinho-Araújo, C. (2014). Sucesso acadêmico na Educação Superior contribuições da Psicologia Escolar. Revista eletrônica de Psicologia, Educação e Saúde, 4(1), 28-46. Disponível em http://docplayer.com.br/9045731Sucesso-academico-na-educacao-superior-contribuicoesda-psicologia-escolar.html

Brasil. Decreto $n^{0}$ 6.096, de 24 de abril de 2007 (Decreto que institui o Programa de Apoio a Planos de Reestruturação das Universidades Federais - REUNI). Disponível em http://www.planalto.gov.br/ccivil_03/_ato20072010/2007/decreto/d6096.htm

Brasil. Decreto $n^{\circ}$ 7.234, de 19 de julho de 2010. Dispõe sobre o Programa Nacional de Assistência Estudantil (PNAES). Disponível em: http://www.planalto.gov.br/ ccivil_03/_ato2007-2010/2010/decreto/d7234.htm

Diéguez, C. R. M. A. (2015). Lugar de jovem é na universidade! Políticas públicas de educação e a ampliação do acesso ao ensino superior brasileiro. Cadernos Adenauer, 1, (1), 45-63. Disponível em http:// www.kas.de/wf/doc/16490-1442-5-30.pdf 
Gebrim, L. B. (2014). Psicologia escolar e educacional no ensino superior: demandas e desafios na história do serviço de atendimento ao estudante da Universidade Federal de Uberlândia. Dissertação de mestrado, Universidade Federal de Uberlândia, Uberlândia.

Lima, P. G. Políticas de educação superior no Brasil na primeira década do século XXI: alguns cenários e leituras. Avaliação: Revista de Avaliação da Educação Superior, 118(1), 85-105. Disponível em http://www. scielo.br/pdf/aval/v18n1/06.pdf

Moscovici, S. (2001). Das Representações Coletivas às Representações Sociais. In: D. Jodelet. Representações Sociais: um domínio em expansão. 1a ed. (pp.45-66). Rio de Janeiro-RJ: EDUERJ.

Ristoff, D. (2014). O novo perfil do campus brasileiro: uma análise do perfil socioeconômico do estudante de graduação. Avaliação: Revista da Avaliação da Educação Superior, 19(3), 723-747. Disponível em http://www. scielo.br/pdf/aval/v19n3/10.pdf
Sampaio, S. M. R. (2009). Explorando possibilidades: o trabalho do psicólogo na Educação Superior. In: Marinho-Araújo, C.M. Psicologia escolar: novos cenários e contextos de pesquisa, formação e prática. Campinas, SP: Alínea.

Neves, C. E. B. (2012). Ensino Superior no Brasil: expansão, diversificação e inclusão. Manuscrito não publicado, Associação de estudos Latinos Americanos. São Francisco, Califórnia.

Vera-Noriega, J. A.; Pimentel, C. E.; Batista de Albuquerque, F. J. (2005). Redes semânticas: aspectos teóricos, técnicos, metodológicos y analíticos. Ra Ximbai, 1(3), 439451. Disponível em http://www.redalyc.org/articulo. oa? id $=46110301$

Zibetti, M. L. T. (2016). A educação como direito: considerações sobre políticas educacionais. In: Campos. H.R, Sousa, M.P.R; Facci, M.G.D. Psicologia e políticas educacionais. Natal, RN: EDUFRN.

Recebido em: 11 de novembro de 2017 Aprovado em: 05 de julho de 2020 